\title{
Tert-butyldimethylsilyl chitosan synthesis and characterization by analytical ultracentrifugation, for archaeological wood conservation
}

\author{
Jennifer M. K. Wakefield ${ }^{1,2} \cdot$ Susan Braovac ${ }^{3} \cdot$ Hartmut Kutzke $^{3} \cdot$ Robert A. Stockman $^{2} \cdot$ Stephen E. Harding $^{1,3}$ (i)
}

Received: 2 March 2020 / Revised: 10 July 2020 / Accepted: 17 July 2020 / Published online: 26 August 2020

(c) The Author(s) 2020

\begin{abstract}
The Oseberg ship is one of the most important archaeological testimonies of the Vikings. After excavation in 1904, the wooden gravegoods were conserved using alum salts. This resulted in extreme degradation of a number of the objects a hundred years later through acid depolymerisation of cellulose and lignin. The fragile condition of the artefacts requires a reconsolidation which has to be done avoiding water as solvent. We synthesized tert-butyldimethylsilyl (TBDMS) chitosan which is soluble in a 50:50 solution of ethyl acetate and toluene. Measurement of its molecular weight, to anticipate its penetration, provided a challenge as the density difference of the polymer and solvent was too small to provide adequate solute redistribution under a centrifugal field, so a two-stage process was implemented (i) determination of the weight-average molar mass of the aqueous soluble activated precursor, chitosan mesylate, $M_{\mathrm{w}, \mathrm{mc}}$ using sedimentation equilibrium with the SEDFIT-MSTAR algorithm, and determination of the degree of polymerisation $D P$; (ii) measurement of the average degree of substitution $D S_{\mathrm{TBDMS}}$ of the TBDMS group on each chitosan monosaccharide monomer unit using NMR, to augment the $M_{\text {w,mc }}$ value to give the molar mass of the TBDMS-chitosan. For the preparation, we find $M_{\mathrm{w}}=9.8 \mathrm{~kg} \cdot \mathrm{mol}^{-1}$, which is within the acceptable limit for penetration and consolidation of degraded wood. Future work will test this on archaeological wood from different sources.
\end{abstract}

Keywords Analytical ultracentrifuge $\cdot$ NMR $\cdot$ Combined molar mass method

\section{Introduction}

The Oseberg collection is in dire need of re-conservation. The Oseberg Viking ship burial was discovered in 1903 and excavated in 1904 (see for example Braovac et al. 2018). The grave mound contained a rich collection of different

Special Issue: Analytical Ultracentrifugation 2019.

Jennifer M. K. Wakefield

jennifer.wakefield1@nottingham.ac.uk

$\triangle$ Stephen E. Harding

steve.harding@nottingham.ac.uk

1 National Centre for Macromolecular Hydrodynamics (NCMH), School of Biosciences, University of Nottingham, Sutton Bonington, Nottingham LE12 5RD, UK

2 School of Chemistry, University of Nottingham, University Park Nottingham, Nottingham NG7 2RD, UK

3 Museum of Cultural History, University of Oslo, St. Olavs plass, Postboks 6762, 0130 Oslo, Norway artefacts; amongst them, many wooden objects which are today displayed at the Viking Ship Museum in Oslo, Norway (www.khm.no). The most degraded wooden artefacts were treated in 1905 with concentrated solutions of alum salts [ $\mathrm{KAl}\left(\mathrm{SO}_{4}\right)_{2} \cdot 12 \mathrm{H}_{2} \mathrm{O}$ and $\mathrm{NH}_{4} \mathrm{Al}\left(\mathrm{SO}_{4}\right)_{2} \cdot 12 \cdot \mathrm{H}_{2} \mathrm{O}$ ] heated to $90{ }^{\circ} \mathrm{C}$. Although this treatment allowed the objects to retain their shape upon drying, it has caused degradation in the long term, as the hot alum treatment produced sulfuric acid which was absorbed by the wood, and which exhibits today an average $\mathrm{pH}$ of about 2-2.5 (Braovac and Kutzke 2012). This sulfuric acid causes hydrolytic cleavage of the $\beta(1 \rightarrow 4)$ glycosidic bond in cellulose and breaks down the cellulose in the wood. There is now very little cellulose left and the lignin in the wood is also heavily oxidised (Braovac and Kutzke 2012; Fors and Sandström 2006; McQueen et al. 2017; Smidsrød et al. 1966). The wood is now very fragile and treatment is required to preserve the artefacts for future generations.

The presence of acid in the wood is of great concern. Since the water-soluble alum supports the remaining wood 
structure, de-acidification by immersion in water could cause the complete collapse of the most degraded artefacts. Therefore, a non-aqueous method is required for the re-treatment of these objects. There are a few non-aqueous treatment methods for wood and they are all derived from fossil fuels (Kučerová 2012). There has, in addition, been a drive in recent years to try to use more natural-based polymers (Cipriani et al. 2010; McHale et al. 2017) rather than petrochemical-based synthetic materials.

Chitosan, a $\beta(1 \rightarrow 4)$ glucan derived from the shells of crabs, lobsters, and other crustaceans, has been selected for its molecular similarity to cellulose in the wood and, as it is a waste product of the canning industry, it is cheap to obtain and sustainable (Ravi Kumar 2000; Younes and Rinaudo 2015). Chitosan has previously been investigated as an aqueous treatment for conservation (Christensen et al. 2015; Walsh et al. 2017). Chitosan in itself is not soluble in organic solvents; it is only soluble in acidic aqueous solutions. Therefore, the polymer requires modification to make it soluble in a suitable organic solvent. These modifications should avoid the use of ester bonds which would be prone to break down particularly in an acidic environment, such as alum-treated wood (Mourya and Inamdar 2008).

We decided to take advantage of a procedure involving mesylation developed some years ago by Rúnarsson et al. (2008) who have made an organic solvent-soluble chitosan derivative, tert-butyldimethylsilyl (TBDMS) chitosan (Rúnarsson et al. 2008) with the TBDMS group being added at both carbon atoms 3 and 6 on the pyranose chains (Fig. 1).

Good solubility [i.e., completely soluble at $10 \%$ (w/v)] was found by Rúnarsson et al. (2008) for chitosan-TBDMS oligomers with a degree of substitution (DS) of 2.2 in a range of different organic solvents such as N-methyl-2-pyrrolidone (NMP), dimethylformamide (DMF), dimethylsulfoxide (DMSO) diethyl ether, triethylamine, pyridine, tetrahydrofuran (THF), acetone, 1-butanol, 2-propanol, ethyl acetate, ethanol, dichloromethane (DCM), and chloroform (Rúnarsson et al.

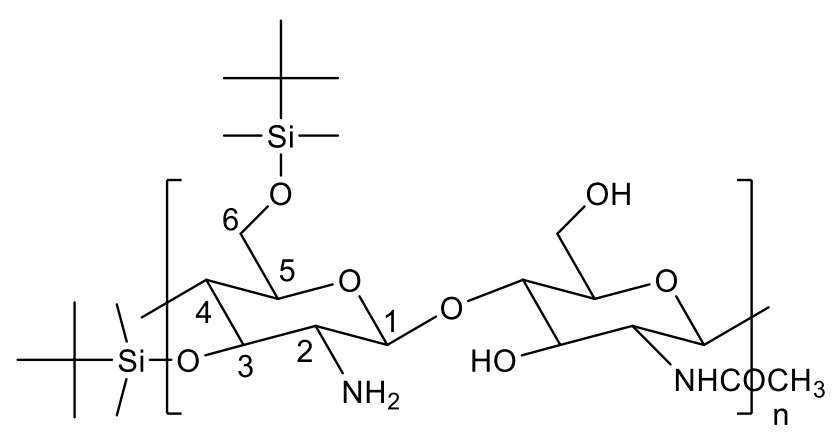

2008). A DS of 1.29 showed reduced solubility in diethyl ether, acetone, and ethanol. The chitosan-TBDMS polymer with a DS of 1.94 had reduced solubility in all solvents, but was still completely soluble at $2.5 \%$ in pyridine, 1-butanol, 2-propanol, and ethyl acetate. Further optimisation by the Runarson et al. team and Song et al. (2010) resulted in a 90\% yield for the mesylate and 96\% yield for the 3,6-di-O-TBDMS-chitosan polymer. The polymer becomes 'superhydrophobic' (Wang and Jiang 2007) and this 'superhydrophobicity' may help to prevent swelling and subsequent shrinkage of the wood.

In this study we therefore, use the Rúnarsson et al. (2008)/ Song et al. (2010) method to produce TBDMS-substituted polymeric chitosan as an organic soluble-modified chitosan for potential consolidant use. For our study, toluene proved a useful solvent for this material which permitted full solubility for the TBDMS chitosan at the sort of scale-up concentrations and volumes which would be useful for potential archaeological wood conservation. For linear PEG polymers used in conservation treatments where aqueous formulations are allowed (e.g., treatment of wood from the Vasa and Mary Rose), it was found that a molar mass of $\sim 0.2-4.0 \mathrm{~kg} \cdot \mathrm{mol}^{-1}$ was useful, and we have recently found that aqueous soluble chitosan of a similar molar mass $\left(\sim 5.0 \mathrm{~kg} \cdot \mathrm{mol}^{-1}\right)$ gives penetration (Wakefield et al. 2018). The non-aqueous analogue, TBDMS chitosan, could be bulkier but shorter which may allow the molar mass to be higher than that of PEG. A backbone of $5.0 \mathrm{~kg} \cdot \mathrm{mol}^{-1}$ seemed reasonable to ensure that it penetrates into the wood. If the polymer is too small, it will not have a sufficient consolidation effect.

As has been discussed before (Wakefield et al. 2018; Harding 2018) for characterizing molar masses of consolidants, the matrix-free and absolute method of sedimentation equilibrium in the analytical ultracentrifuge is particularly attractive. Measurement of the molar mass of a potential consolidant substance with sedimentation equilibrium, however, provides a challenge as the density difference of the TBDMS chitosan and toluene was too small to provide adequate solute redistribution under a centrifugal field: so a two-stage process was implemented.

First, we determine the weight-average molar mass $M_{\mathrm{w}}$ of the aqueous soluble precursor, chitosan mesylate (Mes-CS), $M_{\mathrm{w}, \mathrm{mc}}$, and hence the degree of polymerisation (DP) using sedimentation equilibrium and the SEDFIT-MSTAR algorithm of Schuck, Harding, and coworkers (Schuck et al. 2014). Second, we take the value for the average degree of substitution $D S_{\mathrm{TBDMS}}$ of the TBDMS group onto the chitosan monomer estimated using nuclear magnetic resonance spectroscopy (in the ethyl acetate/toluene solvent) and multiply this by the degree of polymerisation of Mes-CS, finally correcting for the removal of the mesylate.

Fig. 1. 3,6-Silylated chitosan 


\section{Materials and methods}

\section{Generation of a low molar mass $\left(\sim 5 \mathrm{~kg} \cdot \mathrm{mol}^{-1}\right)$ chitosan template}

We follow the oxidative degradative procedure in the presence of ultra-violet radiation of Wakefield et al. (2018) based on an earlier procedure of Wang et al. (2005). Using chitosan (22.0 g) from Norwegian Chitosan Ltd (Gardemoen, Norway) with a degree of acetylation $D A=0.1$, a $4 \%$ (40 g/l) solution was prepared by dissolving (with stirring) chitosan in $0.2 \%$ acetic acid for $1 \mathrm{~h}$ yielding a clear yellow solution. Hydrogen peroxide was then added $(0.2 \%$ after dilution) and the solution was exposed to UV light for $1 \mathrm{~h}$ at $20.0^{\circ} \mathrm{C}$ followed by neutralization with $1 \mathrm{M}$ sodium hydroxide: this causes the chitosan to precipitate out of solution. This solution was then centrifuged and the solid product was washed with deionised water $(3 \times 50 \mathrm{~mL})$ and centrifuged each time $(10,000 \mathrm{rpm}$ for $5 \mathrm{~min})$. The solid product was frozen in an $-80.0^{\circ} \mathrm{C}$ freezer overnight and freeze dried. The five batches yielded a total recovery of $(73.3 \pm 4.0) \%$.

\section{Generation of chitosan mesylate (Mes-CS)}

Prior to the reaction with tert-butyl dimethyl silyl chloride (TBDMSCl), 'intermediate' form of chitosan (chitosan mesylate) was produced facilitating dissolution in dimethyl sulfoxide (DMSO) without compromising the amino group. We use a procedure given by Song et al. (2010) adapted to minimize chain depolymerisation through acid exposure, and use isopropanol rather than ethanol followed by acetone for precipitation. The chitosan $(20.0 \mathrm{~g}, \mathrm{~F}$.W. $165.36,121 \mathrm{mmol})$ was suspended in water $(130 \mathrm{~mL})$ and placed in a $10{ }^{\circ} \mathrm{C}$ ice bath. $15 \mathrm{~mL}$ of methanesulfonic acid (CAS 75-75-2, Alfa Aesar, A13565 lot 10,198,453) was then added slowly, leaving a clear solution. After leaving for $1 \mathrm{~h}$, the product was precipitated after the addition of isopropanol: then filtered and washed twice with isopropanol and then washed with acetone. The product was then filtered once again and left to air dry for $1 \mathrm{~h}$ after which the product was re-dissolved in deionised $\mathrm{H}_{2} \mathrm{O}(15 \mathrm{~mL})$. It was then re-precipitated in acetone $(450 \mathrm{~mL})$ and washed with acetone $(3 \times 125 \mathrm{~mL})$. The resulting white powder was then air dried/vacuum dried (27.83-28.23 g, yield 91.2-92.7\%, 111-112 mmol). Its purity was established by solid-state ATR-FTIR and ${ }^{1} \mathrm{H}$ NMR at $400 \mathrm{MHz}-$ which established a degree of substitution $D S_{\text {mesylate }} \sim 1$ of mesylate. The details of the FTIR and ${ }^{1} \mathrm{H}$ NMR are as follows, where the notations have their usual meaning (see, for example, Rúnarsson et al. 2008; Song et al. 2010):
FTIR: v 3359 (B), 2936 (m), 1635 (vs), 1526 (vs), 777 cm ${ }^{1} .{ }^{1} \mathrm{H}$ NMR (400 MHz, D2O) $\delta 2.8$ (s), 3.2 (m), 3.8-3.9 (m), $4.8(\mathrm{~s})$.

\section{Generation of tert-butyl dimethyl silyl (TBDMS) chitosan}

We follow essentially the procedure of Song et al. (2010) and Rúnarsson et al. (2008). Chitosan mesylate, Mes-CS $(12 \mathrm{~g}, 48 \mathrm{mmol})$, was re-dissolved in dry DMSO $(120 \mathrm{~mL})$, stirring under nitrogen. Imidazole $(32.47 \mathrm{~g}, 477 \mathrm{mmol}$ $5 \times$ excess) and tert-butyl dimethyl silyl chloride (TBDM$\mathrm{SCl})(35.93 \mathrm{~g}, 238 \mathrm{mmol}, 2.5 \times$ excess $)$, were dissolved in dry DMSO $(140 \mathrm{~mL})$ under nitrogen. This was then added dropwise to the chitosan mesylate at room temperature still under nitrogen. After $2 \mathrm{~h}$, dry toluene $(140 \mathrm{~mL})$ was added and left stirring under nitrogen for another $22 \mathrm{~h}$. Deionised $\mathrm{H}_{2} \mathrm{O}(100 \mathrm{~mL})$ was then added and an emulsion formed, which was extracted with a solution of ethyl acetate $(100 \mathrm{~mL})$ and toluene $(50 \mathrm{~mL})$, and then a further ethyl acetate application $(3 \times 75 \mathrm{~mL})$. Ethyl acetate rather than hexane (Rúnarsson et al. 2008) as it facilitated better dissolution. The ethyl acetate fraction was then washed with saturated $\mathrm{NaCl}(3 \times 50 \mathrm{~mL})$. The ethyl acetate was dried over sodium sulfate and the latter was filtered off and the ethyl acetate concentrated on the rotary evaporator until $\sim 30 \mathrm{~mL}$ was left. The product then precipitated in acetonitrile $(300 \mathrm{~mL})$ and washed with acetonitrile $(4 \times 75 \mathrm{~mL})$. This was dried in the fume hood overnight and then dried in a $40.0{ }^{\circ} \mathrm{C}$ vacuum oven to give a white powder (13.27-16.02 g, yield $65.0-78.5 \%)$. The high purity of the product was verified by ATR-FTIR, and the degree of substitution DS evaluated by ${ }^{1} \mathrm{H}$ NMR spectroscopy at $400 \mathrm{MHz}$. The details of the FTIR and 1H NMR are as follows (Rúnarsson et al. 2008; Song et al. 2010): v, 2953-2856 (s), 1689 (vs), 1251, 833, 775 (vs) cm ${ }^{-1}$. ${ }^{1} \mathrm{H}$ NMR (400 MHz, $\mathrm{CDCl}_{3}$ ) d 0.08 (br s), 0.89 (br s), 1.98 (br s), 2.72 (br s), 3.3-3.89 (m), 4.29-4.40 (m), 8.11 (br s).

\section{Sedimentation equilibrium in the analytical ultracentrifuge}

A Beckman XL-I analytical ultracentrifuge (AUC) equipped with Rayleigh interference optics was used. $20 \mathrm{~mm}$ optical path length cells with volumes of $145 \mu \mathrm{L}$ were used for the analysis of the depolymerised chitosan and $12 \mathrm{~mm}$ optical path double sector cells were employed for the chitosan mesylate analysis: solution and solvent (buffer) reference channels were filled to $100 \mu \mathrm{L}$ which gave short solution columns, facilitating equilibrium in $\sim 24 \mathrm{~h}$. A high rotor speed of 40,000 rpm (appropriate for material of the expected size range) at a temperature of $20.0^{\circ} \mathrm{C}$. Scans with Rayleigh interference optics were taken every hour until equilibrium 
was reached: this was assessed using the SEDFIT-Tools-Test approach to equilibrium (courtesy of P. Schuck). Analysis was carried out using SEDFIT-MSTAR (Schuck et al. 2014) which provides the (apparent) weight-average molar mass $M_{\text {w,app }}$ [obtained using the hinge point method-see (Schuck et al. 2014)]. The hinge point proved more appropriate for these samples than the $M^{*}$ method of Creeth and Harding (1982) because of their high polydispersity. Loading concentrations from 0.30 to $1.0 \mathrm{mg} / \mathrm{mL}$ for the chitosan with long path length cells and $0.4-1.0 \mathrm{mg} / \mathrm{mL}$ for short path length cells were employed to monitor for any associative or nonideal effects, which were negligible. Chitosan which had been depolymerised as described before (Wakefield et al. 2018) was dissolved in $0.2 \mathrm{M}$ acetate buffer and the chitosan mesylate in a $0.10 \mathrm{M}$ phosphate-buffered solution supplemented with $\mathrm{NaCl}$ to an ionic strength of 0.10 (Green 1933). A value for the partial specific volume ( $\bar{v})$ of $0.57 \mathrm{~mL} / \mathrm{g}$ was used (Morris et al. 2009).

\section{Treatment of artificially degraded wood}

Birch wood staves were obtained from Norwegian food stores. They were of standard size and shape, $\sim 18 \mathrm{~cm}$ long and $1 \times 1 \mathrm{~cm}$ in cross section with masses from 9 to $11 \mathrm{~g}$. A representative number of birch staves were identified in the light microscope to confirm wood genus (birch, Betula, spp.). The wood was initially waterlogged then immersed in treatment solutions. The birch was then degraded using two solutions a $5 \%$ sulfuric acid solution ( $\mathrm{vol} / \mathrm{vol})$ to degrade the holocellulose fraction and a 5\% sodium hydroxide solution (w/vol) which would cause lignin and hemicellulose degradation. The combined degradation caused by these solutions would also increase porosity in the wood and thus increase degradation rate. The approximate liquid $(\mathrm{L}$, in litres)-to-solid ( $\mathrm{S}$, in kilograms) ratio used for experiments was calculated based on the starting volumes of $1.8 \mathrm{~L}$. The 20 staves gave a total of $176 \mathrm{~g}$ and an $\mathrm{L} / \mathrm{S}$ ratio of 10.2. The acid solution was heated to $90.0^{\circ} \mathrm{C}$ to increase degradation rate (the approximate temperature used during the original alum treatment of Oseberg wood after excavation in 1904) using a water bath. The sodium hydroxide solution was kept at room temperature. Soaking times in each solution lasted for approximately 6 days. Before transferring from one solution to the other, the samples were rinsed in several changes of tap water. After removal from the final degradation bath, a longer period of rinsing was undertaken. The final rinse water $\mathrm{pH}$ was $\sim 7.0$. The wood had a total time of $4784 \mathrm{~h}$ in acid, where $295 \mathrm{~h}$ were at $90{ }^{\circ} \mathrm{C}$, and $1006 \mathrm{~h}$ in base. The wood was then freeze dried for 7 days. The wood density dropped by $(55.4 \pm 1.2) \%$ on average to $(0.382 \pm 0.040) \mathrm{g} /$ $\mathrm{mL}$. Samples were then cut into $1 \mathrm{~cm}$ cubes ( 3 for each treatment and 2 for each control) and then soaked overnight in 50:50 ethyl acetate and toluene followed by transfer to a 10\% TBDMS chitosan in 50:50 ethyl acetate and toluene solution. Controls were left in the solvent. After 2 weeks the cubes were taken out, the surfaces cleaned with a cotton bud loaded with the solvent. The wood pieces were air dried. The photographs, weight, and dimensions were taken before and after this process.

To determine if the polymers penetrated into the wood, scanning electron microscopy coupled with energy-dispersive X-ray spectroscopy (SEM-EDS) was used to map the silicon element present in the polymer. The instrument was an FEI Quanta 450 Scanning Electron Microscope coupled with an Oxford X-Max ${ }^{\mathrm{N}} 50 \mathrm{~mm}^{2}$ detector, using low vacuum mode at (70pa). Spot size 6, HV $15.00 \mathrm{kV}$, working distance $10.4 \mathrm{~mm}$.

\section{Results}

\section{Purity and degree of substitution (DS)}

The purity/chemical integrity of the substituted material, i.e., the inclusion of the TBDMS groups on the chitosan backbone was confirmed by Attenuated Total Reflection Fourier
Fig. 2 Solid-state attenuated total reflection Fourier transform infra-red (ATR-FTIR) spectrum of TBDMS chitosan

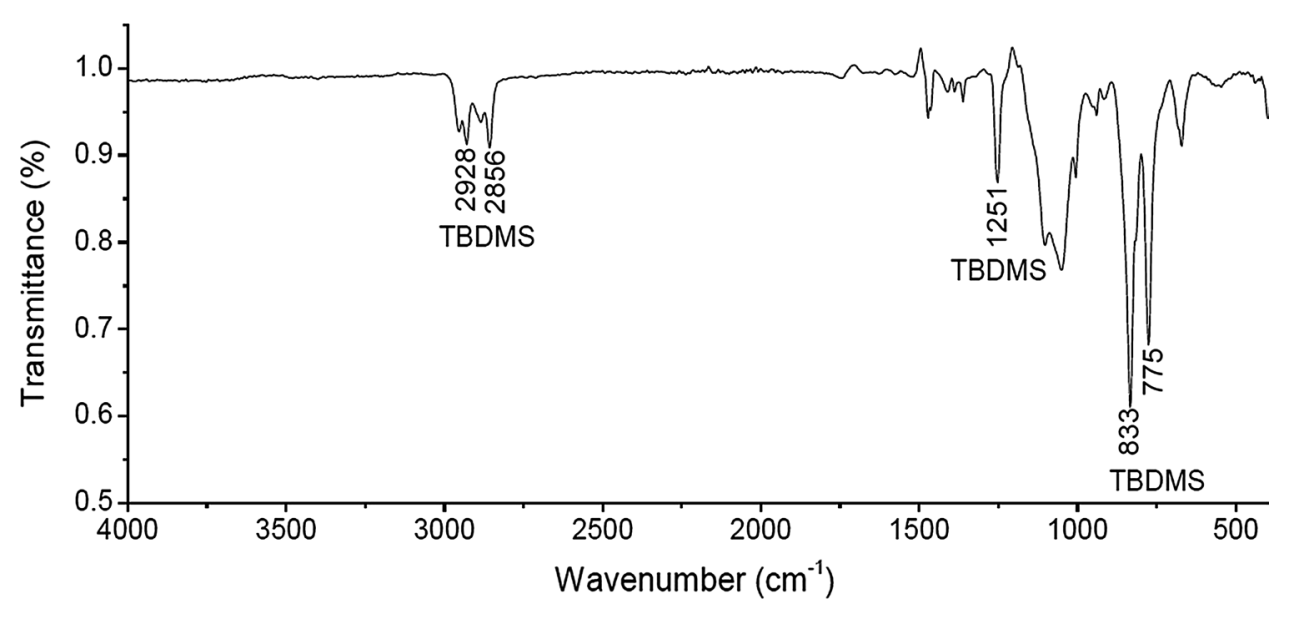


Transform Infra-Red Spectroscopy (ATR-FTIR) wherein diagnostic signals for a silyl group were noted (Fig. 2).

Then, using ${ }^{1} \mathrm{H}$ NMR conducted in deuterated chloroform, we determined the degree of substitution, $D S_{\text {TBDMS }}$ for TBDMS-see Fig. 3. This is found from the ratio of the NMR integral of either set of the hydrogens from the butyl groups of TBDMS chitosan divided by integrals of $\mathrm{H} 2, \mathrm{H} 3$, $\mathrm{H} 4, \mathrm{H} 5, \mathrm{H} 6$, and H6' from the chitosan backbone taking into account the number of protons using the formula given by Rúnarsson and colleagues: $\mathrm{DS}=\left(\left[(\mathrm{CH})_{3}\right] /[\mathrm{H}-2-\mathrm{H}-6\right.$ ' $] \times$ (6/9)) (Rúnarsson et al. 2008). This gave a $D S_{\mathrm{TBDMS}}$ of $\sim 2.3$.

\section{Molar mass of chitosan and the chitosan mesylate intermediate}

Depolymerisation was previously shown to reduce the (weight average) molar mass of an earlier preparation of kitnor chitosan from a weight average molar mass $M_{\mathrm{w}}$ of $(14.2 \pm 1.2) \mathrm{kg} \cdot \mathrm{mol}^{-1}$ to $(4.9 \pm 0.7) \mathrm{kg} \cdot \mathrm{mol}^{-1}$ (Wakefield et al. 2018). We followed this work by scaling up the production in five batches of $22 \mathrm{~g}$. These five batches were combined before chemically modifying the polymer. From Fig. 4 , it can be seen that the molar mass of the combined batch is $M_{\mathrm{w}}=(6.2 \pm 0.3) \mathrm{kg} \cdot \mathrm{mol}^{-1}$. This is an acceptable molar mass as a starting point to develop a conservation material (Wakefield et al. 2018).

Following modification to chitosan mesylate (MesCS) — which helps control the later addition of TBDMSfurther sedimentation equilibrium measurements showed

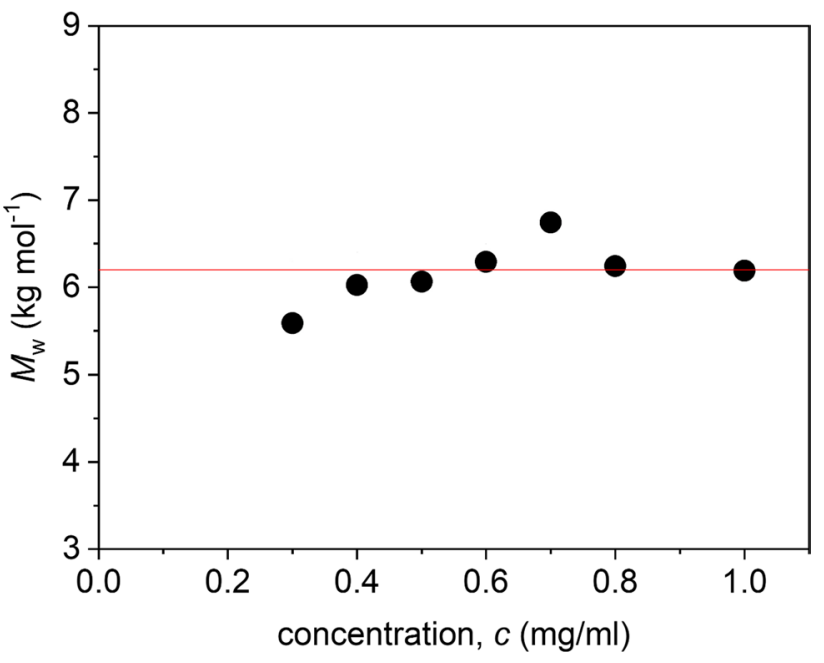

Fig. 4 Plot of $M_{\mathrm{w}, \text { app }}$ from SEDFIT-MSTAR analysis (using the hinge point method) vs loading concentration, $c$ for the scaled-up preparation of depolymerised chitosan run at $40,000 \mathrm{rpm}$ in $I=0.10$ phosphate-chloride buffer. Non-ideality is negligible over the concentration range studied with $M_{\mathrm{w}} \sim M_{\mathrm{w}, \mathrm{app}}=(6.2 \pm 0.3) \mathrm{kg} \cdot \mathrm{mol}^{-1}$

that the (weight average) molar mass $M_{\mathrm{w}}$ was $(5.7 \pm 1.0)$ $\mathrm{kg} \cdot \mathrm{mol}^{-1}$ (Fig. 5) - corresponding to a degree of polymerisation $D P \sim 22.6$ - and showing considerable polydispersity (Fig. 6). SEDFIT-MSTAR analysis (Schuck et al. 2014) offers also an estimate for the z-average molar mass $M_{\mathrm{z}}$ as well as $M_{\mathrm{w}}$, and this leads to an estimate for the polydispersity (in terms of $M_{\mathrm{z}} / M_{\mathrm{w}}$ ) of $\sim 1.9$ for chitosan mesylate compared with $\sim 1.2$ for the untreated chitosan.
Fig. 3. ${ }^{1} \mathrm{H}$ NMR analysisintensity versus frequency (concentration) $\mathrm{f} 1$ in parts per million ppm- of TBDMS chitosan in deuterated chloroform. Integration of the appropriate peaks reveals a degree of substitution $D S_{\text {TBDMS }}=2.3$

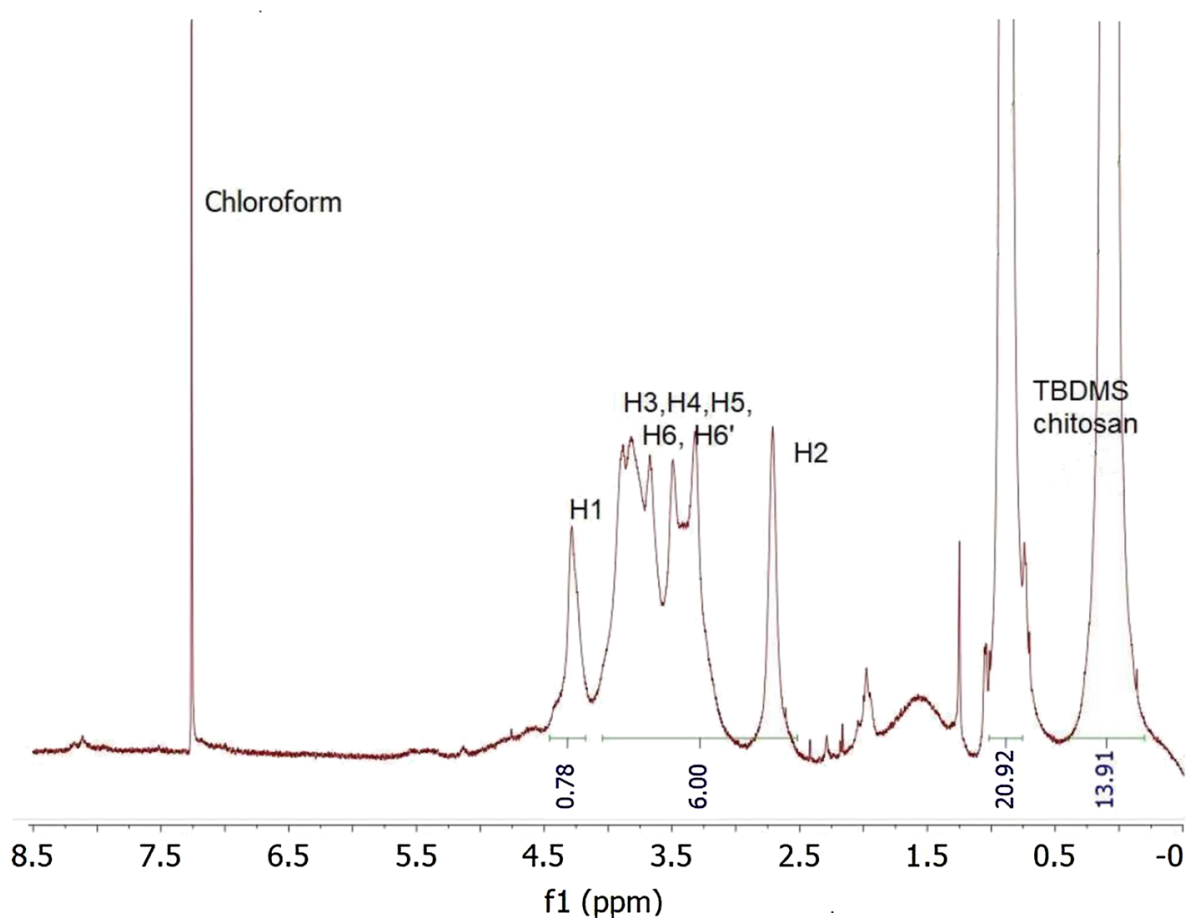




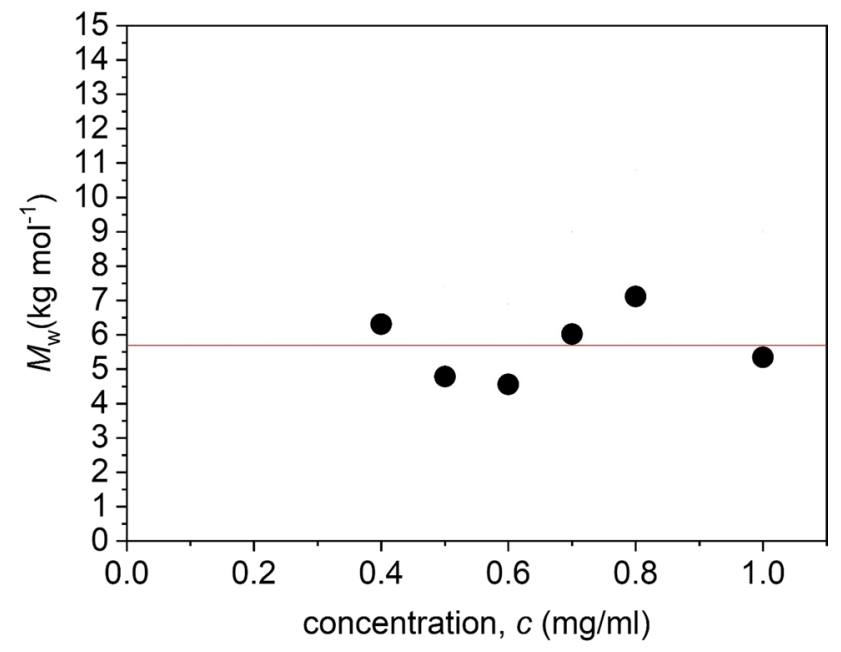

Fig. 5 Plot $M_{\text {w,app }}$ from SEDFIT-MSTAR (estimated from the hinge point) vs loading concentration, $c$ for chitosan mesylate run at $40,000 \mathrm{rpm}$. Non-ideality is negligible over the concentration range studied with $M_{\mathrm{w}} \sim M_{\mathrm{w}, \mathrm{app}}=(5.7 \pm 1.0) \mathrm{kg} \cdot \mathrm{mol}^{-1}$. All samples were run at an equilibrium rotor speed of $40,000 \mathrm{rpm} . I=0.10 \mathrm{M}$ phosphate chloride at $20.0{ }^{\circ} \mathrm{C}$

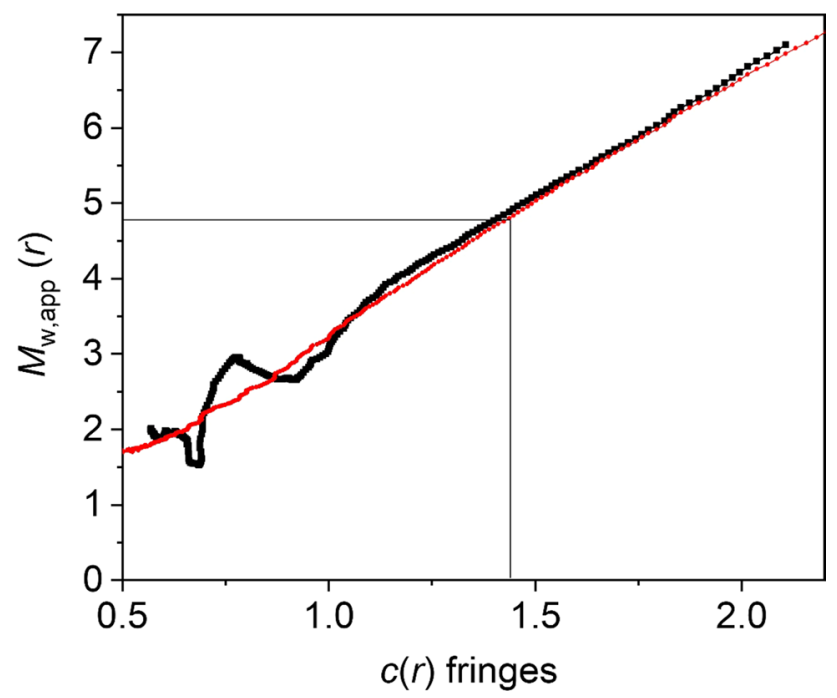

Fig. 6 Point average molecular weights $M_{\mathrm{w}}(r)$ (in $\mathrm{kg} / \mathrm{mol}$ ) as a function of local concentration $c(r)$ in the centrifuge cell (in fringe numbers) at different radial positions $r$ show considerable polydispersity. SEDFIT-MSTAR analysis of chitosan mesylate at $c=0.5 \mathrm{mg} / \mathrm{mL}$. Other information as Fig. 5. The plot also shows the hinge point where the local $c(r)=$ the initial loading concentration $c . I=0.10 \mathrm{M}$ phosphate chloride at $20.0{ }^{\circ} \mathrm{C}$

\section{Evaluation of the molar mass of TBDMS chitosan}

The final step in the molar mass evaluation is to take the value for the degree of substitution of the hydroxyls in a chitosan monosaccharide monomer unit with a TBDMS group determined using ${ }^{1} \mathrm{H}$ nuclear magnetic resonance to calculate the weight-average molar mass of TBDMS chitosan using:

$$
\begin{aligned}
M_{\mathrm{w}}= & M_{\mathrm{w}, \mathrm{mc}}+\left(D P \times D S_{\mathrm{TBDMS}} \times M_{\mathrm{TBDMS}}\right) \\
& -\left(D P \times D S_{\text {mesylate }} \times M_{\text {mesylate }}\right)
\end{aligned}
$$

From the degree of substitution of TBDMS $D S_{\text {TBDMS }}$ of 2.3 (Fig. 3), an average degree of polymerisation $D P \sim 22.6$, molar mass of chitosan mesylate of $5.7 \mathrm{~kg} \cdot \mathrm{mol}^{-1}$, and correcting for the removal of the mesylate which had a degree of substitution $D S_{\text {mesylate }}$ of $\sim 1.0$, we obtain a value of $M_{\mathrm{w}}=9.8 \mathrm{~kg} \cdot \mathrm{mol}^{-1}$ for TBDMS chitosan.

\section{Accuracy of the DS determination by ${ }^{1} \mathrm{HMR}$ spectroscopy}

We have followed the Rúnarsson et al. (2008) method for estimating the average DS of TBDMS residues onto the chitosan molecule. Rúnarsson et al. (2008) do not give the errors/accuracy of this method. However, a very detailed comparison has been given by Hadi et al. (2020) of ${ }^{1} \mathrm{H}$ NMR and stoichiometric methods for DS determination of two other polysaccharides-rice and quinola starches, with different degrees of aceylatation, propionylation, and butyrylation. 24 samples were analyzed in total, and agreement to within $(9.4 \pm 1.4) \%$ was obtained. The additional molar mass due to the TBDMS substitution is, therefore, estimated to be $(3.8 \pm 0.3) \mathrm{kg} / \mathrm{mol}$ leading to an estimate for the molar mass for the intact TBDMS chitosan by this "hybrid" sedimentation equilibrium $-{ }^{1} \mathrm{H}$ NMR method of $(9.8 \pm 1.5) \mathrm{kg} / \mathrm{mol}$.

\section{Potential of Di-TBDMS chitosan for wood conservation}

Figure 7 compares the solubility of TBDMS chitosan in different solvents and shows how TBDMS chitosan starts to precipitate in some solvents over time. The low viscosity in a mixture of toluene and ethyl acetate would allow for archaeological wood application of TBDMS chitosan. Toluene has previously been used in wood conservation and has been found to cause less swelling in wood than polar solvents (Mantanis et al. 1994); however, the solution with TBDMS chitosan would be very viscous, preventing the material entering the cells. Ethyl acetate was previously investigated for wood conservation (McHale et al. 2016) in terms of sustainability and wood swelling and appears preferable to many other solvents. Adjusting the exact DS of TBDMS may allow ethyl acetate to be used alone.

\section{Treatment of artificially degraded wood}

Treatment of artificially degraded wood with $10 \%$ TBDMS chitosan in toluene/ethyl acetate showed a weight gain of $(19.6 \pm 2.0) \%$ after drying, while the solvent control increased by $(8.0 \pm 6.2) \%$. It is possible that not all the 
Fig. 7 Comparison of solubilities of $10 \%$ TBDMS chitosan (w/v) in (a) 1 DCM, 2 2-meTHF, 3 toluene, 4 t-butanol, 5 ethyl acetate, 6 isopropanol, 7 cyclohexane, 8 PET ether, 9 pentane, and 10 methylated spirits. $\mathbf{b} 6$ days later in 12 -meTHF, 2 DCM, 3 ethyl acetate, 4 t-butanol, 5 isopropanol, 6 cyclohexane, 7 methylated spirits, and 8 PET ether.

There is reduced solubility after 6 days in ethyl acetate and isopropanol. c In toluene-ethyl acetate mixture (1) and toluene (2) with vessels tipped to show the lower viscosity of the toluene-ethyl acetate mixture. All measurements were taken at room temperature
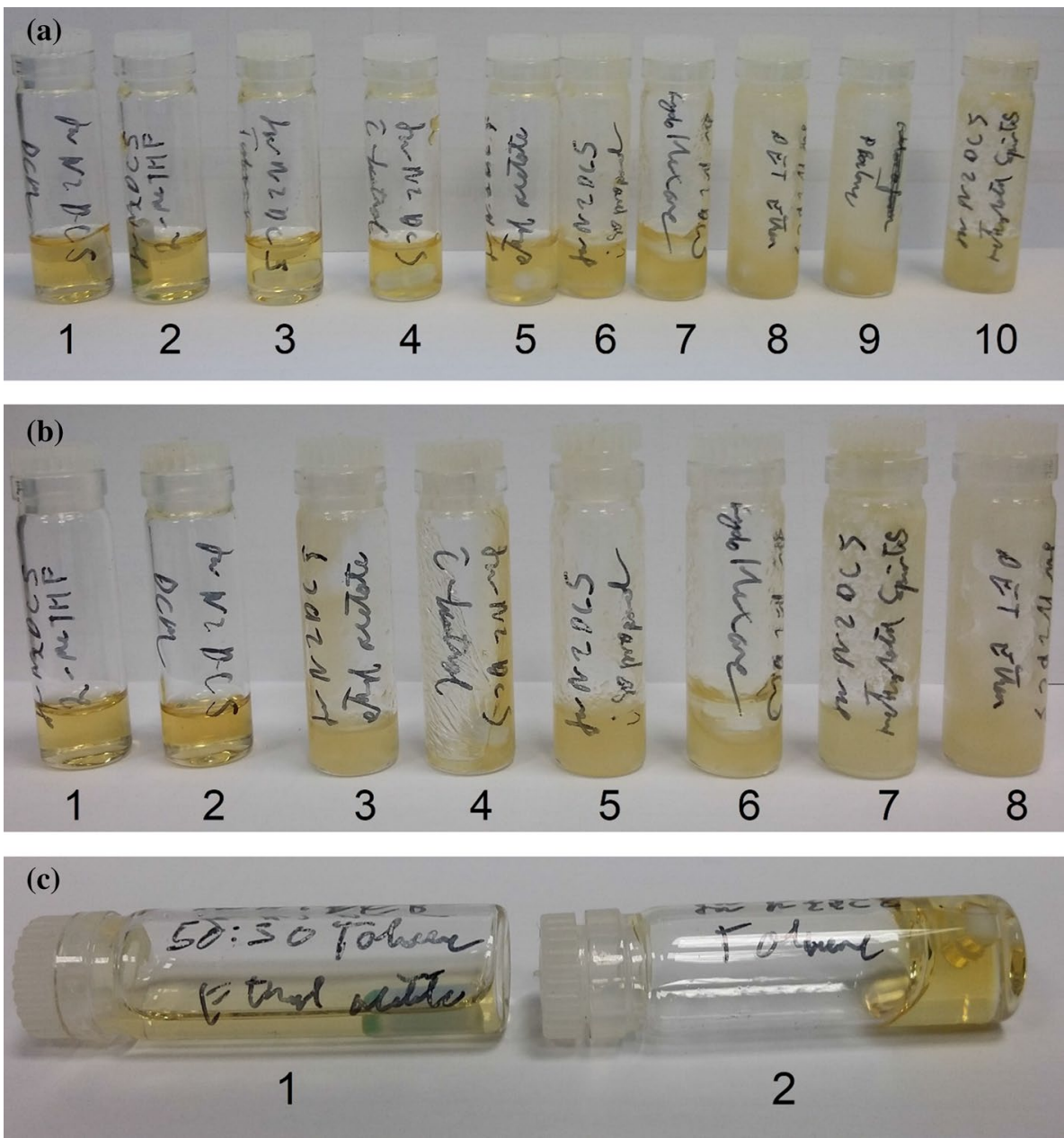

toluene evaporated at the time the samples were weighed. Volume increase of the treated wood by $(3.8 \pm 0.5) \%$ was slightly greater than that for the controls, namely $(2.1 \pm 0.3) \%$, indicating that the treatment caused some swelling. SEM-EDS was carried out on the TBDMS chitosan-treated wood to determine its distribution by mapping for the silicon element in the polymer. Figure 8 shows that the TBDMS chitosan successfully penetrated the wood fully based on the presence of silicon in the core of the sample. SEM images also show that the polymer coats the cell walls rather than simply acting like a filler. This means that it would be easy to re-treat the sample without removing the TBDMS chitosan should it become necessary in the future.
Fig. 8 SEM-EDS images taken from the center of a $1 \mathrm{~cm}$ cube of artificially decayed birch treated with $10 \%$ TBDMS-chitosan in toluene/ethyl acetate. a Image showing the region used for elemental mapping. b EDS map of silicon
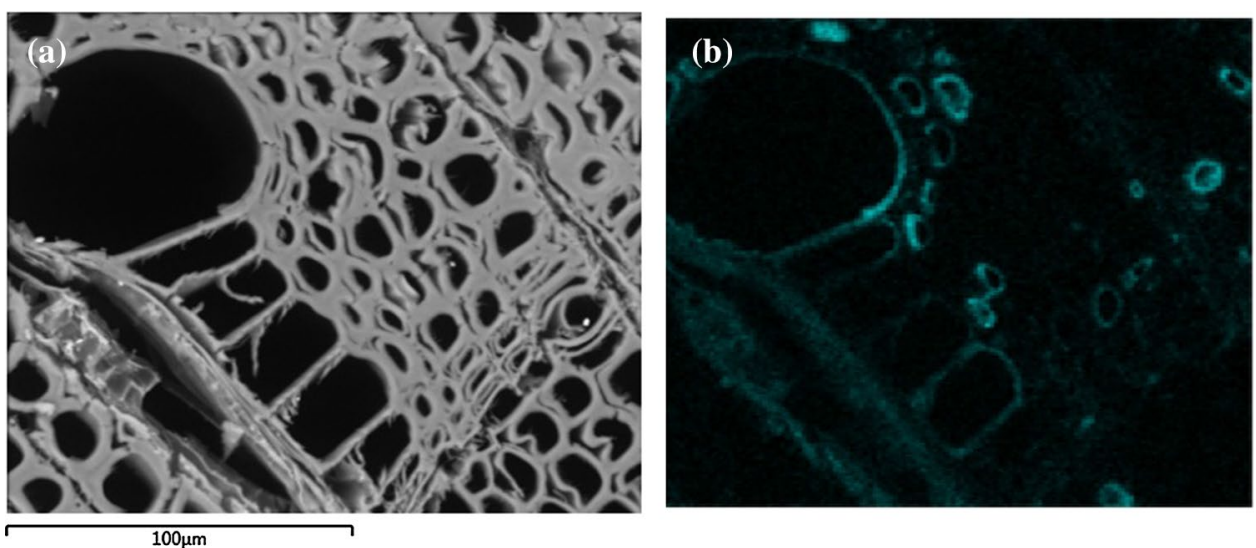


\section{Conclusions}

In this study, we have built on our previous study (Wakefield et al. 2018) successfully reducing the molar mass of chitosan and it making it soluble — to a high yield—in an organic solvent which is what we need for consolidating highly degraded alum-treated wood such as the now perilously fragile Oseberg artefacts from the Viking Ship Museum in Oslo. We have shown that using sedimentation equilibrium in the analytical ultracentrifuge combined with data from NMR, we can successfully avoid the problem of small density increments between polymer and solvent in determining the molecular weights of the promising TBDMS chitosan in a solvent of ethyl acetate and toluene. Our organic toluene/ ethyl acetate soluble chitosan derivative was shown to be characterized by a (weight average) molar mass of $\sim 9.8 \mathrm{~kg} /$ mol, with a degree of polymerisation, $D P$ of, 22.6 and degree of substitution by TBDMS residues of 2.3 .

We then used this polymer to investigate its penetration into small degraded birch samples-which it successfully did, and it did not fill the cell lumens which allows a full retreatment if necessary. The next step is to test the polymer's effectiveness on archaeological wood.

For future consolidation, we are considering first deacidifying the wood with alkaline calcium hydroxide nanoparticles to raise the $\mathrm{pH}$ (Andriulo et al. 2018) and then adding the appropriate consolidant. Both steps of treatment will be conducted using an organic solvent, for the de-acidification as well for the consolidation agent. This is expected to stabilize the wood and prevent future degradation of the wood. A modest $\mathrm{pH}$ environment will also contribute to keep TBDMS chitosan stable over time.

Besides acidity, the presence of metal ions-iron in particular-is a well-known and widespread threat for archaeological wood. The chitosan molecule's ability to chelate metal ions makes it to a promising study object in research on new, bio-inspired, and multifunctional conservation materials. Further research is required to investigate if the modified chitosan retains the ability of untreated chitosan to trap metal ions and to bind to protons. The solubility of TBDMS chitosan in toluene and ethyl acetate shows promise to use the material as an alternative consolidant for archaeological wood that does not tolerate treatments using aqueous solvents.

Acknowledgements This work was carried out as part of the Saving Oseberg Project jointly funded by the Norwegian Ministry of Education and Research and the University of Oslo. JW is supported by a UK EPSRC Centre for Doctoral Training award. Preliminary work on silyl modification was carried out at the Friedrich-Schiller University of Jena with Professor Thomas Heinze's kind permission and was followed up at the University of Nottingham within the Stockman group. Special thanks to the rest of the Saving Oseberg team, the NCMH team, especially Dr. Guy Channell and Dr. Richard Gillis and the Organic
Chemistry team at the University of Nottingham, particularly Johnathan Moore. The paper was presented at the 24th International Analytical Ultracentrifugation Workshop and Symposium, held in Christchurch, New Zealand, 24-29 August, 2019.

\section{Compliance with ethical standards}

Conflict of interest There are no conflicts of interest to declare.

Open Access This article is licensed under a Creative Commons Attribution 4.0 International License, which permits use, sharing, adaptation, distribution and reproduction in any medium or format, as long as you give appropriate credit to the original author(s) and the source, provide a link to the Creative Commons licence, and indicate if changes were made. The images or other third party material in this article are included in the article's Creative Commons licence, unless indicated otherwise in a credit line to the material. If material is not included in the article's Creative Commons licence and your intended use is not permitted by statutory regulation or exceeds the permitted use, you will need to obtain permission directly from the copyright holder. To view a copy of this licence, visit http://creativecommons.org/licenses/by/4.0/.

\section{References}

Andriulo F, Giorgi R, Steindal CC (2018) Nanotechnonologies for the restoration of alum-treated archaeological wood. In Proceedings of the 13th ICOM-CC group on wet organic archaeological materials conference, florence 2016, (ICOM), p 176-183

Braovac S, Kutzke H (2012) The presence of sulfuric acid in alumconserved wood-origin and consequences. J Cult Herit 13:S203-S208

Braovac S, McQueen CMA, Sahlstedt M, Kutzke H, Łucejko JJ, Klokkernes T (2018) Navigating conservation strategies: linking material research on alum-treated wood from the Oseberg collection to conservation decisions. Herit Sci 6:77

Christensen M, Larnøy E, Kutzke H, Hansen FK (2015) Treatment of waterlogged archaeological wood using chitosan- and modified chitosan solutions. Part 1: chemical compatibility and microstructure. J Am Inst Conserv 54:3-13

Cipriani G, Salvini A, Baglioni P, Bucciarelli E (2010) Cellulose as a renewable resource for the synthesis of wood consolidants. J Appl Polym Sci 118:2939-2950

Creeth JM, Harding SE (1982) Some observations on a new type of point average molecular weight. J Biochem Biophys Meth 7:25-34

Fors Y, Sandström M (2006) Sulfur and iron in shipwrecks cause conservation concerns. Chem Soc Rev 35:399-415

Green AA (1933) The preparation of acetate and phosphate buffer solutions of known $\mathrm{pH}$ and ionic strength. J Am Chem Soc 55:2331-2336

Hadi AA, Wiege B, Stabenau S, Marefati A, Rayner M (2020) Comparison of three methods to determine the degree of substitution of quinoa and rice starch acetates, propionates and butyrates: direct stoichiometry, FTIR and 1H-NMR. Foods 9:83. https:// doi.org/10.3390/foods 9010083

Harding SE (2018) The Svedberg Lecture 2017. From nano to micro: the huge dynamic range of the analytical ultracentrifuge for characterising the sizes, shapes and interactions of molecules and assemblies in Biochemistry and Polymer Science. Eur Biophys J 47:697-707

Kučerová I (2012) Methods to measure the penetration of consolidant solutions into 'dry' wood. J Cult Herit 13:S191-S195 
Mantanis GI, Young RA, Rowell RM (1994) Swelling of wood. Part II swelling in organic liquids. Holzforschung 48:480-490

McHale E, Steindal CC, Braovac S, Kutzke H, Benneche T, Harding SE, Gillis R, Adams G (2016) Synthesis and characterisation of lignin-like oligomers as a bio-inspired consolidant for waterlogged archaeological wood. Pure Appl Chem 88:969-977

McHale E, Steindal CC, Kutzke H, Benneche T, Harding SE (2017) In situ polymerisation of isoeugenol as a green consolidation method for waterlogged archaeological wood. Sci Rep 7:46481

McQueen CMA, Tamburini D, Łucejko JJ, Braovac S, Gambineri F, Modugno F, Colombini MP, Kutzke H (2017) New insights into the degradation processes and influence of the conservation treatment in alum-treated wood from the Oseberg collection. Microchem J 132:119-129

Morris GA, Castile J, Smith A, Adams GG, Harding SE (2009) The kinetics of chitosan depolymerisation at different temperatures. Polym Degrad Stab 94:1344-1348

Mourya VK, Inamdar NN (2008) Chitosan-modifications and applications: opportunities galore. React Funct Polym 68:1013-1051

Ravi Kumar MNV (2000) A review of chitin and chitosan applications. React Funct Polym 46:1-27

Rúnarsson ÖV, Malainer C, Holappa J, Sigurdsson STh, Másson M (2008) Tert-butyldimethylsilyl O-protected chitosan and chitooligosaccharides: useful precursors for $\mathrm{N}$-modifications in common organic solvents. Carbohydr Res 343:2576-2582

Schuck P, Gillis RB, Besong TMD, Almutairi F, Adams GG, Rowe AJ, Harding SE (2014) SEDFIT-MSTAR: molecular weight and molecular weight distribution analysis of polymers by sedimentation equilibrium in the ultracentrifuge. Analyst 139:79-92
Smidsrød O, Haug A, Larsen B (1966) The influence of pH on the rate of hydrolysis of acidic polysaccharides. Acta Chem Scand 20:1026-1034

Song W, Gaware VS, Rúnarsson ÖV, Másson M, Mano JF (2010) Functionalized superhydrophobic biomimetic chitosan-based films. Carbohydr Polym 81:140-144

Wakefield JMK, Gillis RB, Adams GG, McQueen CMA, Harding SE (2018) Controlled depolymerisation assessed by analytical ultracentrifugation of low molecular weight chitosan for use in archaeological conservation. Eur Biophys J 47:769-775

Walsh Z, Janeček E-R, Jones M, Scherman OA (2017) Natural polymers as alternative consolidants for the preservation of waterlogged archaeological wood. Stud Conserv 62:173-183

Wang S, Jiang L (2007) Definition of superhydrophobic states. Adv Mater 19:3423-3424

Wang S-M, Huang Q-Z, Wang Q-S (2005) Study on the synergetic degradation of chitosan with ultraviolet light and hydrogen peroxide. Carbohydr Res 340:1143-1147

Younes I, Rinaudo M (2015) Chitin and chitosan preparation from marine sources. Structure, properties and applications. Mar Drugs 13:1133-1174

Publisher's Note Springer Nature remains neutral with regard to jurisdictional claims in published maps and institutional affiliations. 